\title{
Health of children less than 5 years old in an upper middle income country: parents' views
}

\author{
Paul Andrew Bourne \\ Department of Community Health and Psychiatry, Faculty of Medical Sciences, Kingston, Jamaica; paulbourne1@yahoo.com
}

Received 25 November 2009; revised 10 December 2009; accepted 16 December 2009.

\section{ABSTRACT}

Health literature in the Caribbean, and in particular Jamaica, has continued to use objective indices such as mortality and morbidity to examine children's health. The current study uses subjective indices such as parent-reported health conditions and health status to evaluate the health of children instead of traditional objective indices. The study seeks 1) to examine the health and health care-seeking behaviour of the sample from the parents' viewpoints; and 2) to compute the mean age of the sample with a particular illness and describe whether there is an epidemiological shift in these conditions. Two nationally representative cross-sectional surveys were used for this study (2002 and 2007). The sample for the current study is 3,062 respondents aged less than 5 years. For 2002, the study extracted a sample of 2,448 under 5 year olds from the national survey of 25,018 respondents, and 614 under 5 year olds were extracted from the 2007 survey of 6,728 respondents. Parents-reported information was used to measure issues on children under 5 years old. In $2007,43.4 \%$ of the sample had very good health status; $46.7 \%$ good health status; $2.5 \%$ poor health and $0.3 \%$ very poor health status. Almost $15 \%$ of children had illnesses in 2002, and 6\% more had illnesses in 2007 over 2002. In 2002, the percentage of the sample with particular chronic illnesses was: diabetes mellitus (0.6\%); hypertension (0.3\%) and arthritis (0.3\%). However, none was recorded in 2007. The mean age of children less than 5 years old with acute health conditions (i.e. diarrhoea, respiratory diseases and influenza) increased over 2002. In 2007, 43.4\% of children less than 5 years old had very good health status; $46.7 \%$ good health status; $7.1 \%$ fair health status; $2.5 \%$ poor and $0.3 \%$ very poor health status. The association between health status and parent- reported illness was $-\mathrm{x}^{2}(\mathrm{df}=4)=57.494, P<$ 0.001-with the relationship being a weak one, correlation coefficient $=0.297$. A cross-tabulation between health status and parent-reported diagnosed illness found that a significant statistical correlation existed between the two variables $-\mathrm{x}^{2}(\mathrm{df}=16)=26.621, P<0.05$, cc $=0.422$, - with the association being a moderate one, correlation coefficient $=0.422$. A cross tabulation between health status and health careseeking behaviour found a significant statistical association between the two variables $-\mathrm{x}^{2}(\mathrm{df}=4)$ $=10.513, P<0.033$-with the correlation being a weak one-correlation coefficient $=0.281$. Rural children had the least health status. The health disparity that existed between rural and urban less than 5 year olds showed that this will not be removed simply because of the abolition of health care utilization fees.

Keywords: Health Conditions; Acute Condition; Chronic Conditions; Health Status; Child Health; Jamaica

\section{INTRODUCTION}

In many contemporary nations, objective indices such as life expectancy, mortality and diagnosed morbidity are still being widely used to measure the health of people, a society and/or a nation [1-6]. The World Health Organisation (WHO) in the Preamble to its Constitution in the 1940s wrote that health is more important than disease, as it expands to the social, psychological and physical wellbeing of an individual [7]; and lately that during the $21^{\text {st }}$ century the emphasis must be on healthy life expectancy $[8,9]$. In keeping with its opined emphasis, the WHO formulated a mathematical approach that diminished life expectancy by the length and severity of time spent in illness as the new thrust in measuring and examining health. Although healthy life expectancy removes time spent 
in illness and severity of dysfunctions, it fundamentally rests on mortality. The WHO therefore, instead of moving forward, has given some scholars, who are inclined to use objective indices in measuring health, a guilty feeling about continuing this practice.

The Caribbean, and in particular Jamaica, continues to use mortality and morbidity to measure the health of children or infants [1-6]. The use of mortality, morbidity and life expectancy is the practice of Caribbean scholars, and is widely used in Jamaica by the: Ministry of Health (MOHJ) [10]; Statistical Institute of Jamaica (STATIN) [11]; Planning Institute of Jamaica (PIOJ) [12]; PIOJ and STATIN [13] as well as the Pan American Health Organization (PAHO) [14] in measuring health. In spite of the conceptual definition opined by the WHO in the Preamble to its Constitution in 1946, the health of children who are less than 5 years old in Jamaica is still measured primarily by using mortality and morbidity statistics. Recently a book entitled 'Health Issues in the Caribbean' [15] had a section on Child Health; however the articles were on 1) nutrition and child health development [16] and 2) school achievement and behaviour in Jamaican children [17], indicating the void in health literature regarding health conditions.

An extensive review of health literature in the Caribbean region found no study that has used national survey data to examine the health status of children less than 5 years of age. The current study fills this gap in the literature by examining the health status of children less than 5 years of age using cross-sectional survey data which are based on the views of patients. The objectives of this study are 1) to examine the health and health care-seeking behaviour of the sample; and 2) to evaluate the mean age of the sample with a particular illness and to describe whether there is an epidemiological shift in these conditions.

\section{MATERIALS AND METHODS}

\subsection{Sample}

The current study used two secondary nationally representative cross-sectional surveys (for 2002 and 2007) to carry out this work. The sub-samples are children less than 5 years old, and the only criterion for selection was being less than 5 years old. The sample in the current study is 3,062 respondents of ages less than 5 years. For 2002, a sub-sample of 2,448 less than-5 year olds was extracted from the national survey of 25,018 respondents in 2002, and information on 614 less than-5 year olds was extracted from the 2007 survey. The survey (Jamaica Survey of Living Conditions) began in 1989 to collect data from Jamaicans in order to assess government policies. Since 1989, the JSLC has added a new module each year in order to examine that phenomenon, which is critical within the nation [18,19]. In 2002, the focus was on 1) social safety nets, and 2) crime and vic- timization, while for 2007, there was no focus.

\subsection{Methods}

Stratified random sampling technique was used to draw the sample for the JSLC. This design was a two-stage stratified random sampling design where there was a Primary Sampling Unit (PSU) and a selection of dwellings from the primary units. The PSU is an Enumeration District (ED), which comprises a minimum of 100 residences in rural areas and 150 in urban areas. An ED is an independent geographical unit that shares a common boundary. This means that the country was grouped into strata of equal size based on dwellings (EDs). Based on the PSUs, a listing of all the dwellings was made, and this became the sampling frame from which a Master Sample of dwellings was compiled, which in turn provided the sampling frame for the labour force. One third of the Labour Force Survey (i.e. LFS) was selected for the JSLC $[18,19]$. The sample was weighted to reflect the population of the nation [18-20].

The JSLC 2007 was conducted in May and August of that year; while the JSLC 2002 was administered between July and October of that year. The researchers chose this survey based on the fact that it is the latest survey on the national population, and that that it has data on the self-reported health status of Jamaicans. An administered questionnaire was used to collect the data from parents on children less than 5 years old, and the data were stored, retrieved and analyzed using SPSS for Windows 16.0 (SPSS Inc; Chicago, IL, USA). The questionnaire was modelled on the World Bank's Living Standards Measurement Study (LSMS) household survey. There are some modifications to the LSMS, as the JSLC is more focused on policy impacts. The questionnaire covered areas of socio-demographic variables-such as education; daily expenses (for the past 7 days); food and other consumption expenditures; inventory of durable goods; health variables; crime and victimization; social safety net and anthropometry. The non-response rates for the 2002 and 2007 surveys were 26.2\% and $27.7 \%$ respectively. The non-response includes refusals and cases rejected in data cleaning.

\subsection{Measures}

Social class: This variable was measured based on the income quintiles: The upper classes were those in the wealthy quintiles (quintiles 4 and 5); the middle class was quintile 3 and the poor were the lower quintiles (quintiles 1 and 2).

Age is a continuous variable in years.

Health conditions (i.e. parent-reported illness or parent-reported dysfunction): The question was asked: "Is this a diagnosed recurring illness?” The answering options are: Yes, Cold; Yes, Diarrhoea; Yes, Asthma; Yes, Diabetes; Yes, Hypertension; Yes, Arthritis; Yes, Other; and No. 
Self-rated health status: "How is your health in general?” And the options were: Very Good; Good; Fair; Poor and Very Poor.

Medical care-seeking behaviour was taken from the question 'Has a health care practitioner, healer or pharmacist been visited in the last 4 weeks?' with there being two options: Yes or No.

Parent-reported illness status. The question is 'Have you had any illness other than due to injury (for example a cold, diarrhoea, asthma, hypertension, diabetes or any other illness) in the past four weeks? Here the options were Yes or No.

\subsection{Statistical Analysis}

Descriptive statistics, such as mean, standard deviation (SD), frequency and percentage were used to analyze the socio-demographic characteristics of the sample. Chi-square was used to examine the association between non-metric variables, and Analysis of Variance (ANOVA) was used to test the relationships between metric and non-dichotomous categorical variables, whereas an independent sample t-test was used to examine the statistical correlation between a metric variable and a dichotomous categorical variable. The level of significance used in this research was 5\% (i.e. 95\% confidence interval).

\section{RESULTS}

\subsection{Demographic Characteristic of Sample}

In 2002, the sex ratio was 98.8 males (less than 5 years old) to 100 females (less than 5 years old), which shifted to 116.2 less than-5 year old males to 100 less than-5 year old females. The sample over the 6 year period (2002 to 2007) revealed internal migrations to urban zones (Table 1): In 2002, 59.6\% of respondents resided with their parents and/or guardians in rural areas, which declined to $5.07 \%$. The percentage of children less than 5 years of age whose parents were in the poorest $20 \%$ fell to $25.4 \%$ in 2007 over $29.6 \%$ in 2002. In 2007 over 2002, 1.7 times less children less than 5 years of age were taken to public hospitals, compared to 1.2 times less taken to private hospitals (Table 1). Approximately $6 \%$ more children less than 5 years were ill in 2007 over 2002. Based on Table 1, less than-5 year olds with particular chronic illnesses had: diabetes mellitus (0.6\%); hypertension $(0.3 \%)$ and arthritis (0.3\%). However, none was recorded in 2007.

There were some occasions on which the response rates were less than 50\%: In 2002, health care-seeking behaviour was $14.3 \%$; parent-reported diagnosed health conditions, $14.2 \%$; and visits to health care institutions, 8.9\% (Table 1). For 2007, the response rate for health care-seeking behaviour was 20.2\%; parent-reported diagnosed health conditions, $20.2 \%$, and less than $11 \%$ for cost of medical care.

\subsection{Health Conditions}

Based on Table 1, the percentage of less than-5 year olds with particular acute conditions saw a decline in colds and asthmatic cases, as well as chronic conditions. Figure 1 revealed that in 2007 the mean age of children less than 5 years old with acute health conditions (i.e. diarrhoea, respiratory diseases and influenza) increased over 2002. On the other hand, the mean age of those with unspecified illnesses declined from 1.76 years ( $S D=1.36$ years) to 1.64 years ( $\mathrm{SD}=1.36$ years). Concomitantly, the greatest mean age of the sample was 2.71 years ( $\mathrm{SD}=1.21$ years) for asthmatics in 2007 and 2.59 years (1.24 years) in 2002. It should be noted here that the mean age of a child less than 5 years of age in 2002 with diabetes mellitus was 1.50 years (2.12 years).

\subsection{Health Status}

In 2002, the JSLC did not collect data on the general health status of Jamaicans, although this was done in 2007. Therefore, no figures were available for health status for 2002. In 2007, 43.4\% of children less than 5 years old had very good health status; $46.7 \%$ good health status; $7.1 \%$ fair health status; $2.5 \%$ poor and $0.3 \%$ very poor health status. The response rate for the health status question was $96.9 \%$.

Ninety-seven percent of the sample was used to examine the association between health status and parent- reported illness $-x^{2}(\mathrm{df}=4)=57.494, P<0.001$-with the relationship being a weak one, correlation coefficient $=0.297$. Table 2 revealed that $24.2 \%$ of children less than 5 years of age who reported an illness had very good health status, compared to 2 times more of those who did not report an illness. One percent of parents indicated that their children (of less than 5 years) who had no illness had poor health status, compared to 5.6 times more of those with illness who had poor health status.

\subsection{Health Conditions, Health Status and Medical Care-Seeking Behaviour}

A cross-tabulation between health status and parentreported diagnosed illness found that a significant statistical correlation existed between the two variables $-x^{2}$ $(\mathrm{df}=16)=26.621, P<0.05$, cc=0.422, -with the association being a moderate one, correlation coefficient $=0.422$ (Table 3). Based on Table 3, children less than 5 years old with asthma were less likely to report very good health status (5.9\%), compared to those with colds (30.5\%); diarrhoea (22.2\%); and unspecified health conditions (22.7\%).

When health status by parent-reported illness (in \%) was examined by gender, a significant statistical relationship was found, $P<0.001$ : males $-x^{2}(\mathrm{df}=4)$ 
Table 1. Socio-demographic characteristic of sample, 2002 and 2007.

\begin{tabular}{|c|c|c|c|c|}
\hline \multirow{2}{*}{ Variable } & \multicolumn{2}{|c|}{2002} & \multicolumn{2}{|c|}{2007} \\
\hline & $\mathbf{n}$ & $\%$ & $\mathbf{n}$ & $\%$ \\
\hline \multicolumn{5}{|l|}{ Sex } \\
\hline Male & 1216 & 49.7 & 330 & 53.7 \\
\hline Female & 1231 & 50.3 & 284 & 46.7 \\
\hline \multicolumn{5}{|l|}{ Income quintile } \\
\hline Poorest 20\% & 725 & 29.6 & 156 & 25.4 \\
\hline Poor & 554 & 22.6 & 140 & 22.8 \\
\hline Wealthy & 402 & 16.4 & 117 & 19.1 \\
\hline Wealthiest 20\% & 293 & 12.0 & 75 & 12.2 \\
\hline \multicolumn{5}{|l|}{ Self-reported illness } \\
\hline Yes & 345 & 14.9 & 125 & 20.8 \\
\hline No & 1969 & 85.0 & 475 & 79.2 \\
\hline \multicolumn{5}{|l|}{ Visits to health care facilities (hospitals) } \\
\hline Private, yes & 17 & 7.8 & 5 & 6.7 \\
\hline \multicolumn{5}{|l|}{ Area of residence } \\
\hline Rural & 1460 & 59.6 & 311 & 50.7 \\
\hline Semi-urban & 682 & 27.9 & 125 & 20.4 \\
\hline Urban & 306 & 12.5 & 178 & 29.0 \\
\hline \multicolumn{5}{|l|}{ Health (or, medical) care-seeking behaviour } \\
\hline Yes & 221 & 63.3 & 76 & 61.3 \\
\hline No & 128 & 36.7 & 48 & 38.7 \\
\hline \multicolumn{5}{|l|}{ Health insurance coverage } \\
\hline Yes, private & 211 & 9.0 & 66 & 11.1 \\
\hline Yes, public & $*$ & $*$ & 33 & 5.5 \\
\hline No & 2123 & 91.0 & 496 & 83.4 \\
\hline \multicolumn{5}{|l|}{ Self-reported diagnosed health conditions } \\
\hline \multicolumn{5}{|l|}{ Acute } \\
\hline Cold & 185 & 53.3 & 60 & 48.4 \\
\hline Diarrhoea & 20 & 5.8 & 9 & 7.3 \\
\hline Diabetes mellitus & 2 & 0.6 & 0 & 0 \\
\hline Hypertension & 1 & 0.3 & 0 & 0 \\
\hline Arthritis & 1 & 0.3 & 0 & 0 \\
\hline Other (unspecified) & 54 & 15.6 & 22 & 17.7 \\
\hline Not diagnosed & 38 & 11.0 & 16 & 12.9 \\
\hline Number of visits to health care institutions & \multicolumn{2}{|c|}{$1.53(\mathrm{SD}=0.927)$} & \multicolumn{2}{|c|}{$1.43(\mathrm{SD}=0.989)$} \\
\hline Duration of illness Mean (SD) & \multicolumn{2}{|c|}{8.51 days (6.952 days) } & \multicolumn{2}{|c|}{8.07 days (7.058 days) } \\
\hline \multicolumn{5}{|l|}{ Cost of medical care } \\
\hline Public facilities Median (Range) in USD & \multicolumn{2}{|c|}{$2.36(157.26)^{1}$} & \multicolumn{2}{|c|}{$0.00(64.62)^{2}$} \\
\hline Private facilities Median (Range) in USD & \multicolumn{2}{|c|}{$13.76(117.95)^{1}$} & \multicolumn{2}{|c|}{$10.56(49.71)^{2}$} \\
\hline
\end{tabular}

${ }^{1} \mathrm{USD} 1.00=$ Ja. $\$ 50.87 ;{ }^{2} \mathrm{USD} 1.00=$ Ja. $\$ 80.47$

*In 2002, all health insurance coverage was private and this was change in 2005 to include some public option.

$=25.932, P<0.05, \mathrm{cc}=0.320$, and females $-x^{2}(\mathrm{df}=4)=$ 39.675, $P<0.05$, сс $=0.356$. The health statuses of males less than 5 years old in the very good and good categories were greater than those of females (Figure 2). However, the females had greater health statuses in fair and poor health status than males, with more males reporting very poor health status than females.

Based on Figure 3, even after controlling health status and parent-reported illness (in \%) by area of residence, a significant statistical association was found: urban $-x^{2}$ $(\mathrm{df}=3)=10.358, P<0.05, \mathrm{cc}=0.238$; semi-urban $-x^{2}$ $(\mathrm{df}=3)=9.887, P=0.021, \mathrm{cc}=0.273$, and rural $-x^{2}(\mathrm{df}$ $=3)=45.978, P<0.001$, сc $=0.365$. Concomitantly,
Table 2. Health status by self-reported illness.

\begin{tabular}{ccc}
\hline \multirow{2}{*}{ Health status } & \multicolumn{2}{c}{ Self-reported illness } \\
\cline { 2 - 3 } & Yes & No \\
& n (\%) & $\mathbf{n}(\%)$ \\
\hline Very good & $30(24.2)$ & $227(48.3)$ \\
Good & $61(49.2)$ & $217(46.2)$ \\
Fair & $23(18.5)$ & $19(4.0)$ \\
Poor & $9(7.3)$ & $6(1.3)$ \\
Very poor & $1(0.1)$ & $1(0.2)$ \\
Total & 124 & 470 \\
\hline
\end{tabular}

$x^{2}(\mathrm{df}=4)=57.494, P<0.001, \mathrm{cc}=0.297, \mathrm{n}=594$ 


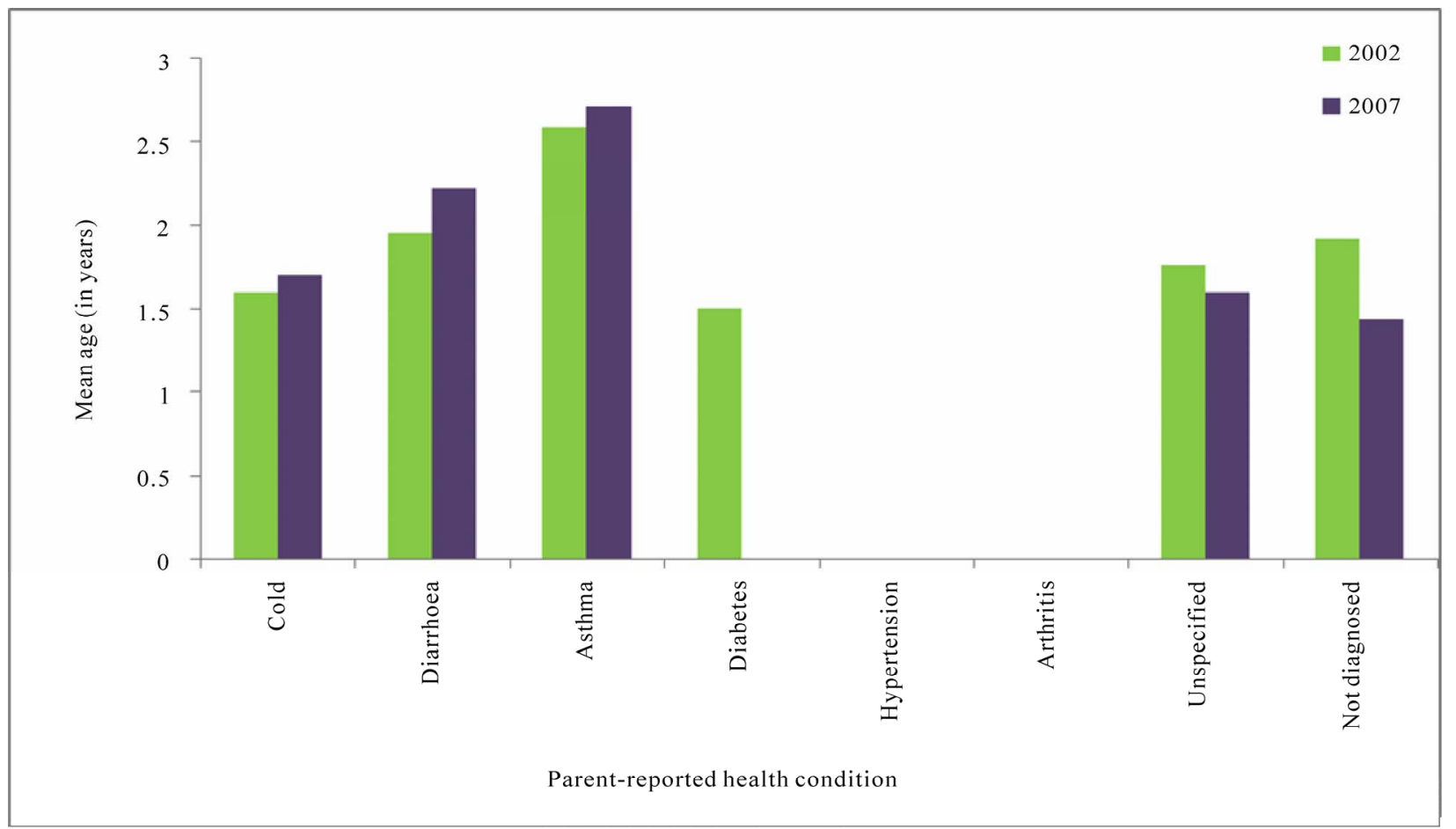

Figure 1. Mean age of health conditions of children less than 5 years old, 2002 and 2007.

Table 3. Health status by self-reported diagnosed illness.

\begin{tabular}{cccccc}
\hline Health & \multicolumn{5}{c}{ Self-reported diagnosed illness } \\
\cline { 2 - 6 } status & Cold & Diarrhoea & Asthma & Unspecified & No \\
\hline Very & 18 & $2(22.2)$ & $1(5.9)$ & $5(22.7)$ & 5 \\
good & $(30.5)$ & & & & $(31.3)$ \\
& 31 & $5(55.6)$ & 4 & $11(50.0)$ & 8 \\
Good & $(52.5)$ & & $(23.5)$ & & $(50.0)$ \\
& 7 & $2(22.2)$ & 8 & $3(13.6)$ & 3 \\
Fair & $(11.9)$ & & $(47.1)$ & & $(18.8)$ \\
& 2 & $0(0.0)$ & 4 & $3(13.6)$ & 0 \\
Poor & $(3.4)$ & & $(23.5)$ & & $0.0)$ \\
Very & 1 & $0(0.0)$ & $0(0.0)$ & $0(0.0)$ & 0 \\
good & $(1.7)$ & & & & \\
Total & 59 & 9 & 17 & 22 & 16 \\
\hline
\end{tabular}

children less than 5 years of age were the least likely to have very good health status (19.4\%) compared to rural (25.8\%) and semi-urban children (25.9\%). Furthermore, the respondents who resided in urban areas were 2.1 times more likely to have parent-reported very poor health status, compared to rural respondents.

In examining health status and reported illness (in \%) by social classes, significant statistical relationships were found, $P<0.05$ : poor-to-poorest classes $-x^{2}(\mathrm{df}=4)=$ 52.374, $P=0.021$, cc $=0.393$; middle class $-x^{2}(\mathrm{df}=3)$ $=8.821, P=0.032$, cc $=0.259$, and wealthy class $-x^{2}(\mathrm{df}$ = 3 ) $=10.691, P=0.02$, cc $=0.234$. Based on Figure 4, middle class children who are less than 5 years old had the greatest very good health status (37\%) compared to the wealthy class (26.8\%) and the poor-to-poorest classes (16.1\%). Fourteen percent of poor-to-poorest class children who are less than 5 years old had at most poor health status compared to $0 \%$ of the middle class and $4.9 \%$ of the wealthy class, while $1.8 \%$ of poor-topoorest classes less than 5 years of age had very poor health status.

When health status and parent-reported illness was examined by age, sex, social class, and area of residence, the correlation was a weak one-correlation coefficient = 0.295, $\mathrm{P}<0.001, \mathrm{n}=583$. A cross tabulation between health status and health care-seeking behaviour found a significant statistical association between the two variables $-x^{2}(\mathrm{df}=4)=10.513, P<0.033$-with the correlation being a weak one-correlation coefficient $=0.281$. A child less than 5 years old was 2.44 times more likely to be taken for medical care if he/she had at most poor health status. On the other hand, a child who had very good health status was 1.97 times more likely not to be taken to health care practitioners (Figure 5).

In 2007, an examination of the health care-seeking behaviour and parent-reported illness of the sample revealed no statistical correlation $-x^{2}(\mathrm{df}=1)=0.430, P=$ 0.618. Sixty-two percent of the sample, who was ill, was taken to health care practitioners, while $38.5 \%$ were not. On the other hand, more were taken for medical care than in 2007 in the 4-week period of the survey. No statistical correlation was noted for the aforementioned variables in $2002-x^{2}(\mathrm{df}=1)=1.188, P=0.276$. Of those who reported ill, $63.7 \%$ were taken to health care practitioners. 


\section{DISCUSSIONS}

Infant mortality has been declining since the 1970s, and this has further decreased since 2004 [14]; this, as the literature shows, is not a good measure of health. The current study found that, using general health status, children less than 5 years of age in Jamaica had good health. The findings revealed that 90 out of every 100 less than-5 year olds had at least good health status, with 44 out of every 100 having very good health status. In spite of the good health status of less than- 5 year olds in Jamaica in 2007, 20.8\% of them had an illness in the

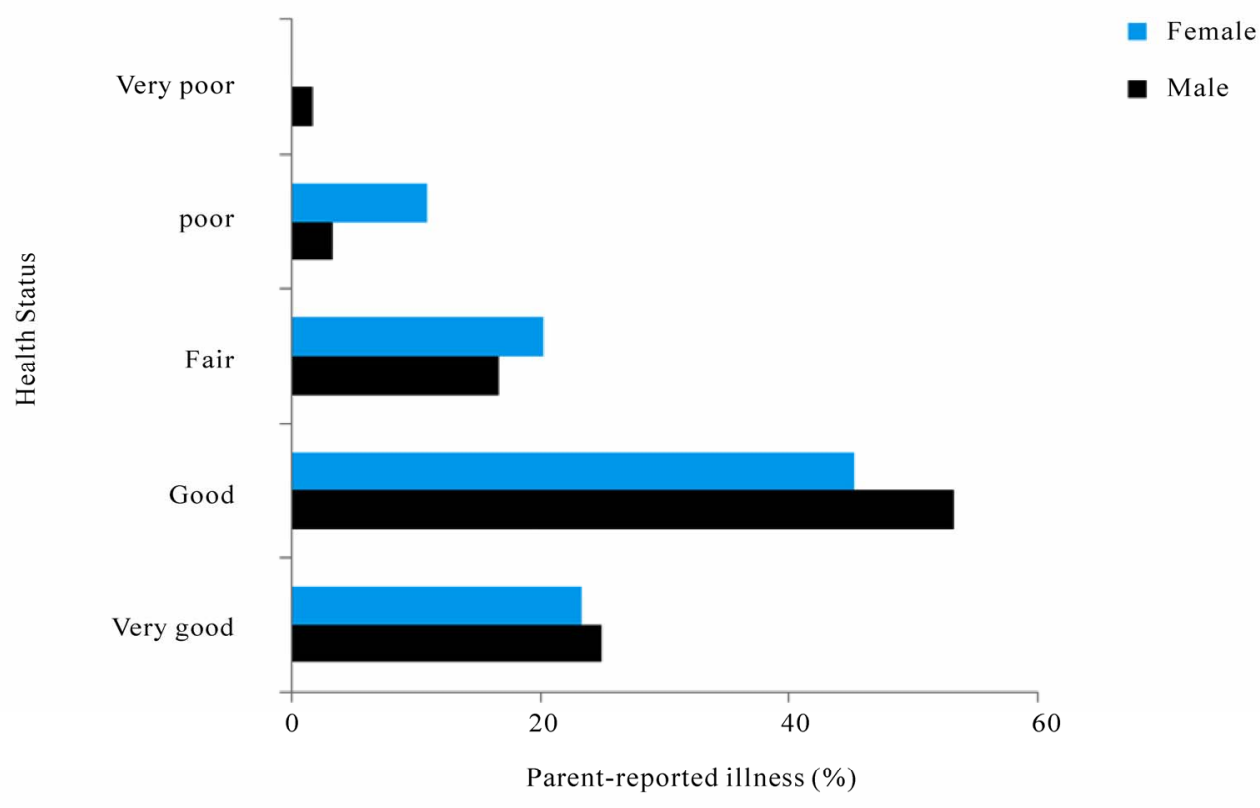

Figure 2. Health status by Parent-reported illness (in \%) examined by gender.

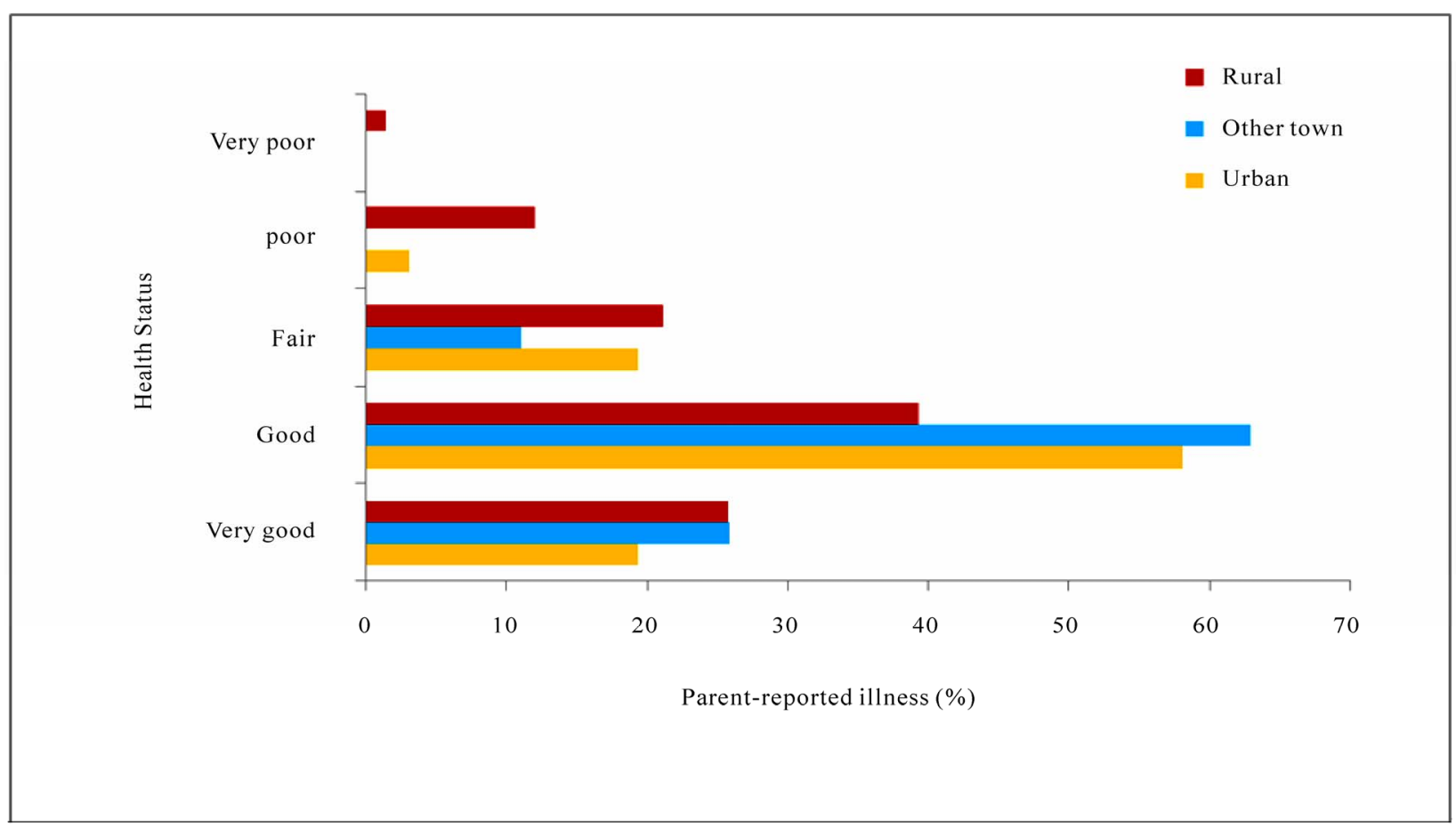

Figure 3. Health status by parent-reported illness (in \%) examined by area of residence. 


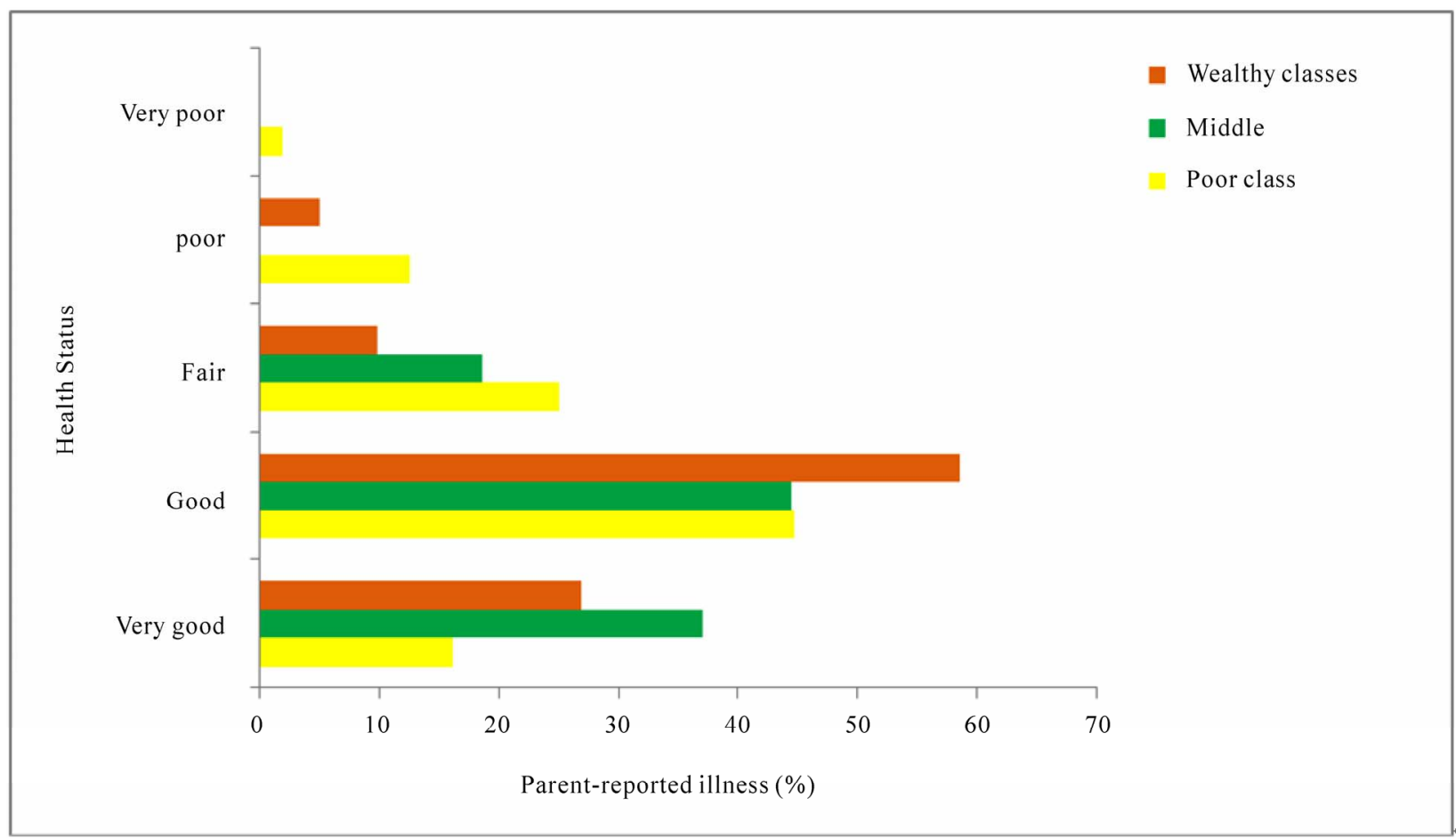

Figure 4. Health status by parent-reported illness (in \%) examined by social classes.

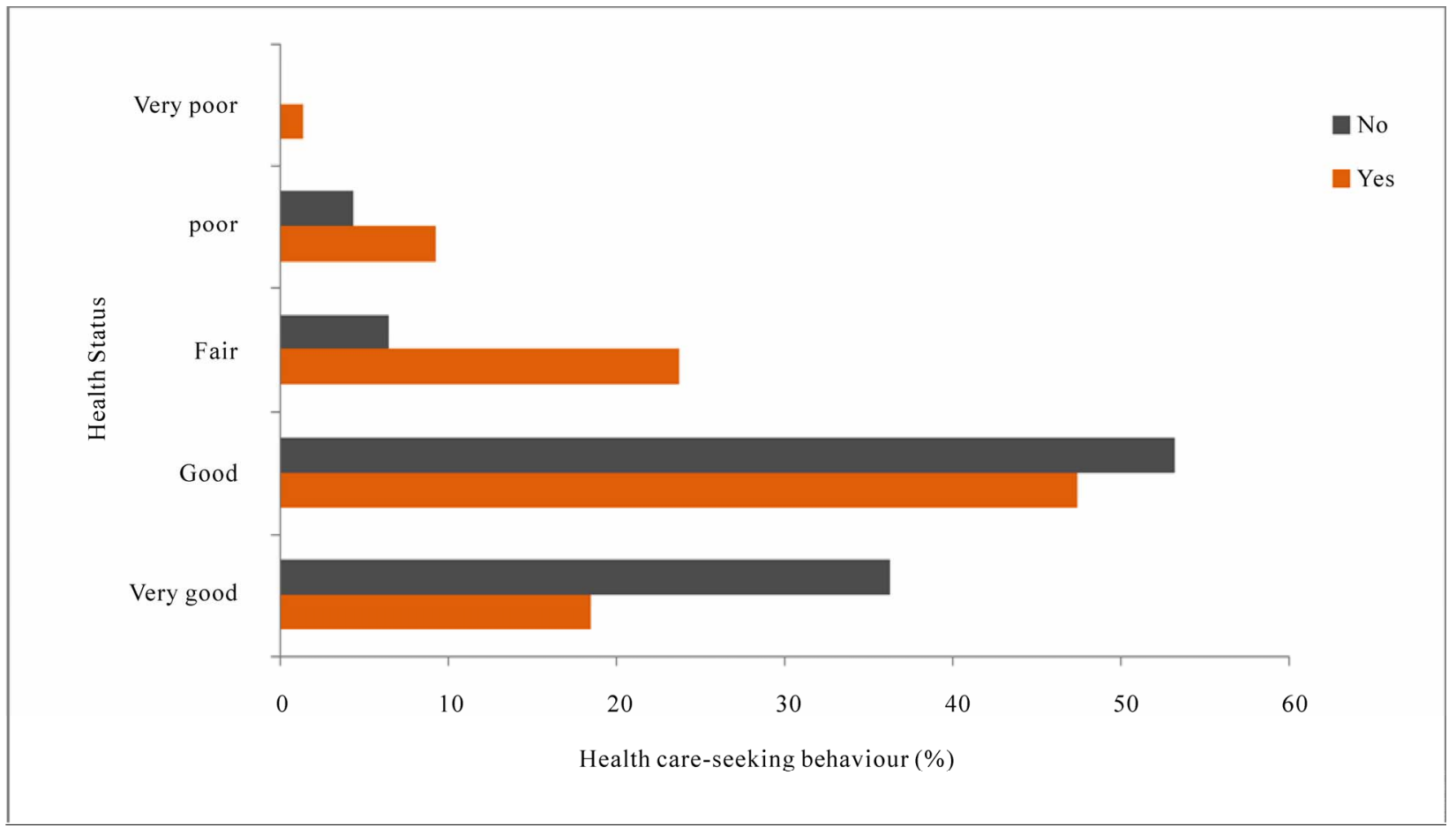

Figure 5. Health status by health care-seeking behaviour.

4-week period of the survey, which is a $5.9 \%$ increase over 2002. It is interesting to note the shift in this study away from specific chronic illnesses. In 2002, 30 out of every 1,000 less than-5 year olds in Jamaica were diag- nosed with hypertension and arthritis (i.e. parentreported), with 60 out of 1,000 having been parent-reported with diabetes mellitus. None such cases were found in 2007, suggesting that in the case of the children who had 
those particular chronic illnesses, their parents had either migrated with them or they had died. Concomitantly, the country is seeing a reduction in children less than 5 years old with colds; however, marginal increases were seen in diarrhoea, asthma and unspecified health conditions over the last 6 years. Although there were increased reported cases of illness over the studied period, in 2007, 62 out of every 100 ill children were taken to medical practitioners, and this fell from 64 in every 100 in 2002. One of the arguments put forward by some people is that what retards or abates health care-seeking behaviour is medical cost. With the abolition of health care user fees for children since 2007, the culture must be playing a role in parents and/or guardians not taking children who are ill to medical care facilities for treatment.

Medical cost cannot be divorced from the expenditure that must be incurred in taking the child to the health care facility. In 2007, 25 out of every 100 children less than 5 years of age had parents and/or guardians who were less than the poverty line. Although this has declined by $4.2 \%$ since 2002 , it nevertheless means that there are children whose parents are incapacitated by other factors. Marmot [21] opined that the financial inability of the poor is what accounts for their lowered health status, compared to other social classes. The current study concurs with the findings of Marmot, as it was revealed that children less than 5 years of age from poor households had the least health status. This means that poverty is not merely eroding the health status of poor Jamaicans, but that equally it is decreasing the health status of poor children.

Rural poverty in Jamaica is at least twice as great as urban poverty, and approximately 4 times more than semi-urban [13], which provides another explanation for the poor health status of children less than 5 years of age. The current study found that $3.2 \%$ of those children dwelling in urban zones recorded at most poor health status, compared to $13.6 \%$ of rural children, suggesting that the health status of the latter group is 4.3 times worse than the former. This means that poverty in rural zones is exponential, eroding the quality of life of children who are less than 5 years old. Poverty in semi-urban areas was $4 \%$ which is 2.5 times less than that for the nation; and those less than 5 years of age recorded the greatest health status, supporting Marmot's perspective that poverty erodes the health status of a people. Hence, the decline in health care-seeking behaviour for this sample is embedded in the financial constraints of parents and/or guardians as well as their geographical challenges. The terrain in rural zones in Jamaica is such that medical care facilities are not easily accessible to residents compared to urban dwellers. With this terrain constraint comes the additional financial burden of attending medical care facilities at a location which is not in close proximity to the home of rural residents, and this accounts for the vast health disparity between rural and urban children. As a result of the above, the removal of health care utilization fees for children less than 18 years of age does not correspond to an increased utilization of medical care services, or lowered numbers of unhealthy children less than 5 years of age. If rural parents are plagued with financial and location challenges, their children will not have been immunized or properly fed, and their nutritional deficiency would explain the health disparity that exists between them and urban children who have easier access to health care facilities.

The removal of health care utilization fees is not synonymous with an increased utilization of medical care for children less than 5 years old, as $46.5 \%$ of the sample attended public hospitals for treatment in 2002, and after the abolition of user fees in April 2007 utilization fell by 1.7 times compared to 2002. In order to understand stand why there is a switch from health care utilization to mere survival, we can examine the inflation rate. In 2007, the inflation rate was $16.8 \%$ which is a $133 \%$ increase over 2002 (i.e. $7.2 \%$ ), which translates into a $24.7 \%$ increase in the prices of food and non-alcoholic beverages, and a $3.4 \%$ increase in health care costs [22]. Here the choice is between basic necessities and health care utilization, which further erodes health care utilization in spite of the removal of user fees for children.

Health status uses the individual self-rating of a person's overall health status [23], which ranges from excellent to poor. Health status therefore captures more of people's health than diagnosed illness, life expectancy, or mortality. However, how good a measure is it? Empirical studies show that self-reported health is an indicator of general health. Schwarz \& Strack [24] cited that a person's judgments are prone to systematic and nn-systematic biases, suggesting that it may not be a good measure of health. Diener, [25] however, argued that the subjective index seemed to contain substantial amounts of valid variance, indicating that subjective measures provide some validity in assessing health, a position with which Smith concurred [26]. Smith [26] argued that subjective indices do have good construct validity and that they are a respectably powerful predictor of mortality risks [27], disability and morbidity [27], though these properties vary somewhat with national or cultural contexts. Studies have examined self-reported health and mortality, and have found a significant correlation between a subjective and an objective measure [27-29]: life expectancy [30]; and disability [28]. Bourne [30] found that the correlation between life expectancy and self-reported health status was a strong one (correlation coefficient, $\mathrm{R}=0.731$ ); and that self-rated health accounted for $53 \%$ of the variance in life expectancy. Hence, the issue of the validity of subjective and objective indices is good, with Smith [26] opining that the construct validity between the two is a good one.

The current research found that parent-reported illness and the health status of children less than 5 years of age 
are significantly correlated. However, the statistical association was a weak one (correlation coefficient=0.297), suggesting that only $8 \%$ of the variance in health status can be explained by parent-reported children's illnesses. This is a critical finding which reinforces the position that self-reported illnesses (or health conditions) only constitute a small proportion of people's health. Therefore, using illness to measure the health status of children who are less than 5 years of age is not a good measure of their health, as illness only accounts for $8 \%$ of health status. However, based on Bourne's work [30], health status is equally as good a measure of health as life expectancy. One of the positives for the using of health status instead of life expectancy is its coverage in assessing more of people's general health status by using mortality or even morbidity data.

\section{CONCLUSIONS}

In summary, the general health status of children who are less than 5 years old is good; however, social and public health programmes are needed to improve the health status of the rural population, which will translate into increased health status for their children. The health disparity that existed between rural and urban children less than 5 years of age showed that this will not be removed simply because of the abolition of health care utilization fees. In keeping with this reality, public health specialists need to take health care to residents in order to further improve the health status of children who are less than 5 years old.

\subsection{Conflict of Interest}

The author has no conflict of interest to report.

\subsection{Disclaimer}

The researcher would like to note that while this study used secondary data from the Jamaica Survey of Living Conditions, 2007, none of the errors that are within this paper should be ascribed to the Planning Institute of Jamaica or the Statistical Institute of Jamaica as they are not there, but owing to the researcher.

\section{REFERENCES}

[1] Lindo, J. (2006) Jamaican perinatal mortality survey, Jamaica Ministry of Health. Kingston, 1-40.

[2] McCarthy, J.E. and Evans-Gilbert, T. (2009) Descriptive epidemiology of mortality and morbidity of health-indicator diseases in hospitalized children from western Jamaica. American Journal of Tropical Medicine and Hygiene, 80, 596-600.

[3] Domenach, H. and Guengant, J. (1984) Infant mortality and fertility in the Caribbean basin. Cah Orstom (Sci Hum), 20, 265-72.
[4] Rodriquez, F.V., Lopez, N.B., and Choonara, I. (2002) Child health in Cuba. Archives of Disease in Childhood, 93, 991-3.

[5] McCaw-Binns, A., Holder, Y., Spence, K., GordonStrachan, G., Nam, V., and Ashley, D. (2002) Multisource method for determining mortality in Jamaica: 1996 and 1998. Department of Community Health and Psychiatry, University of the West Indies. International Biostatistics Information Services. Division of Health Promotion and Protection, Ministry of Health, Jamaica. Statistical Institute of Jamaica, Kingston.

[6] McCaw-Binns, A.M., Fox, K., Foster-Williams, K., Ashley, D.E., and Irons, B. (1996) Registration of births, stillbirths and infant deaths in Jamaica. International Journal of Epidemiology, 25, 807-813.

[7] World Health Organization (1948) Preamble to the Constitution of the World Health Organization as adopted by the International Health Conference, New York, June 19-22, 1946; signed on July 22, 1946 by the representatives of 61 States (Official Records of the World Health Organization, 2, 100) and entered into force on April 7, 1948. "Constitution of the World Health Organization, 1948.” In Basic Documents, 15th Edion, World Health Organization, Geneva.

[8] World Health Organization (2004) Healthy life expectancy 2002: 2004 world health report. World Health Organization, Geneva.

[9] World Health Organization (2000) WHO issues new healthy life expectancy rankings: Japan number one in new 'healthy life' system. World Health Organization, Washington D. C. \& Geneva.

[10] Jamaica Ministry of Health (1992-2007) Annual report 1991-2006. Jamaica Ministry of Health, Kingston.

[11] Statistical Institute of Jamaica (1981-2009) Demographic statistics, Statistical Institute of Jamaica, Kingston.

[12] Planning Institute of Jamaica (1981-2009) Economic and social survey. Planning Institute of Jamaica, Kingston.

[13] Planning Institute of Jamaica and Statistical Institute of Jamaica (1989-2009) Jamaica Survey of Living Conditions, 1988-2008. PIOJ and STATIN, Kingston.

[14] Pan American Health Organization (2007) Health in the Americas, volume II Countries. Pan American Health Organization, Washington DC.

[15] Morgan, W. Ed. (2005) Health issues in the Caribbean. Ian Randle, Kingston.

[16] Walker, S. (2005) Nutrition and child health development. In Morgan, W. Ed., Health issues in the Caribbean, Ian Randle, Kingston, 15-25.

[17] Samms-Vaugh, M., Jackson, M., and Ashley, D. (2005) School achievement and behaviour in Jamaican children. In Morgan, W. Ed. Health issues in the Caribbean, Ian Randle, Kingston, 26-37.

[18] Statistical Institute of Jamaica. (2008) Jamaica survey of living conditions, 2007, Kingston, Jamaica. Statistical Institute of Jamaica, Planning Institute of Jamaica and Derek Gordon Databank, University of the West Indies, Kingston, Jamaica.

[19] Statistical Institute of Jamaica. (2003) Jamaica survey of living conditions. Statistical Institute of Jamaica, Kingston, Planning Institute of Jamaica and Derek Gordon Databank, University of the West Indies.

[20] World Bank, Development Research Group, (2002). 
Poverty and human resources. Jamaica Survey of Living Conditions (LSLC) 1988-2000: Basic Information.

[21] Marmot, M. (2002) The influence of income on health: Views of an Epidemiologist. Does money really matter? Or is it a marker for something else? Health Affair, 21, 31-46.

[22] Bourne, P.A. (2009) Impact of poverty, not seeking medical care, unemployment, inflation, self-reported illness, health insurance on mortality in Jamaica. North American Journal of Medical Sciences, 1, 99-109.

[23] Kahneman, D. and Riis, J. (2005) Living, and thinking about it, two perspectives. In Huppert, F. A., Kaverne, B. and N. Baylis, The Science of Well-Being, Oxford University Press.

[24] Schwarz, N. and Strack, F. (1999) Reports of subjective well-being: Judgmental processes and their methodological implications. In Kahneman, D., Diener, E., Schwarz, N. Eds., Well-Being: The Foundations of Hedonic Psychology. Russell Sage Foundation, New York, 61-84.
[25] Diener, E. (1984) Subjective well-being. Psychological Bulletin, 95, 542-75.

[26] Smith, J. (1994) Measuring health and economic status of older adults in developing countries. Gerontologist, 34, 491-6.

[27] Idler, E.L. and Benjamin, Y. (1997) Self-rated health and mortality: A review of twenty-seven community studies. Journal of Health and Social Behavior, 38, 21-37.

[28] Idler, E.L. and Kasl, S. (1995) Self-ratings of health: Do they also predict change in functional ability? Journal of Gerontology, 50, S344-S353.

[29] Schechter, S., Beatty, P., and Willis, G.B. (1998) Asking survey respondents about health status: Judgment and response issues. In Schwarz, N., Park, D., Knauper, B., and Sudman, S. Eds., Cognition, Aging, and SelfReports, Taylor and Francis, Ann Arbor.

[30] Bourne, P.A. (2009) The validity of using self-reported illness to measure objective health. North American Journal of Medical Sciences, 1, 232-238. 